\title{
Dentistry in the post covid-19 world- are we prepared?
}

Vrushali Abhyankar ${ }^{*}$, Gabriela Fernandes ${ }^{2}$, Vinay Jain ${ }^{3}$, Paul Luepke ${ }^{4}$

${ }^{1}$ Assistant Professor, Periodontology, Diplomate, American Academy of Periodontology, UTHSC, College of Dentistry, 875, Union Avenue, C513 Memphis, TN-38163

${ }^{2}$ Department of Oral Biology, Suny, Buffalo, New-York, USA

${ }^{3}$ Associate Professor, Prosthodontics, UTHSC, College of Dentistry, 875, Union Avenue, C513 Memphis, TN-38163

${ }^{4}$ Associate Professor and Chair, Dept of Periodontology UTHSC, College of Dentistry, 875, Union Avenue, Memphis, TN 38163

*Corresponding author: Vrushali Abhyankar, 1Assistant Professor, Periodontology, Diplomate, American Academy of Periodontology, UTHSC, College of Dentistry, 875, Union Avenue, C513 Memphis, TN-38163.

Received date: June 10, 2020; Accepted date: July 01, 2020; published date: July 10, 2020

Citation: Vrushali Abhyankar, Gabriela Fernandes, Vinay Jain, Paul Luepke. Dentistry in the post covid-19 world- are we prepared? J Clinical Research and Reports, 4(5); DOI:10.31579/2690-1919/096

Copyright: (C) 2020 Vrushali Abhyankar. This is an open access article distributed under the Creative Commons Attribution License, which permits unrestricted use, distribution, and reproduction in any medium, provided the original work is properly cited.

\section{Abstract}

Background: Covid -19 pandemic has affected dental profession tremendously and has placed dentists and dental professionals in the very high exposure risk jobs. Practicing dentistry requires the provider to be in close proximity of the patients and their oral cavity. Many dental procedures tend to generate aerosols owing to the use of an air rotor or highspeed handpiece. The impact of Covid -19 on dentistry, like all other professions is ever evolving and newer guidelines are published almost every day. The authors also examine the ethical, psychological and financial implications of this pandemic to the dental professionals as well as patients. The important role of organized dentistry is highlighted in facilitating change to adapt to the new norm and implement the safer practice guidelines.

Conclusions: The authors conclude that significant changes need to be undertaken to protect patients, dental professionals, and auxiliary personnel.

Keywords: Covid-19; dentistry; PPE; ethics; aerosols; implications; coronavirus

\section{Introduction}

The global outbreak of Corona virus disease 2019, also known as COVID19, declared as a pandemic by WHO in March 2020 has altered our lives in ways not imagined only a few months ago. A pneumonia of unknown origin was initially reported in December 2019 in the Wuhan province of China, later discovered to be caused by the novel SARS- CoV2 (Severe acute respiratory syndrome Corona virus-2) and WHO named the new disease caused by this virus as Covid-19. Corona viruses belonging to the family of Orthocoronavirinae are non- segmented, singled stranded, positive sense, enveloped RNA viruses that have protein spikes on the surface arranged similar to crown, as seen in electron-microcopy, hence the name corona virus. The size of the virus ranges from 60 to $140 \mathrm{~nm}$ in diameter with $9-14 \mathrm{~nm}$ protein spikes responsible for the host specificity of the virus. $(1,2)$

Covid-19 is a primary infection of the respiratory system causing illnesses whose range of severity is across the board, from being asymptomatic to acute respiratory syndrome to systemic shock and death. (3) Apart from having no cure and no vaccine the persistent ongoing challenge to its clinical management is due to the highly mutative nature of the virus and the potential for rapid spread. Covid-19 manifests clinically as fever, cough, and fatigue after an average incubation period of 5.2 days. The increasing severity of symptoms to pneumonia is dependent on the patient's age, immune status of the patient and co-existing morbidities. In some cases symptoms like sputum production, neurological manifestations like headache, anosmia (4) and in rare cases hemoptysis, diarrhea, and lymphopenia may also occur. (5) Symptomatic patients may or may not have had contact with a known Covid-19 patient making the disease more ominous. A majority of patients run an asymptomatic or mild course and need to be quarantined to prevent droplet spread. Social distancing, washing hands regularly and wearing a facemask were some of the measures recommended by WHO to prevent the spread of air borne disease. These global measures have curtailed the rampant spread of disease, however as countries lift the strict social stay-home protocols and life crawls back to a new normal, every profession with possible human contact will be governed by new rules. The impact of Covid -19 on dentistry, like all other professions is ever evolving and newer guidelines are published almost every day.

The Occupational safety and health organization places dentists in the very high exposure risk jobs category due to their high potential for exposure to known and suspected Covid-19 cases and the potential for dental procedures to produce aerosols. (6) The American dental association had given a directive to cease all elective dental procedures since Mid-March 2020. As majority of dental practices are set to open and will continue to remain open in the new post Covid-19 world, significant changes need to be undertaken to protect patients, dental professionals, auxiliary personnel.

\section{Aerosols in Dentistry}

Aerosol by definition is a suspension of solid particles or liquids in gases. In dentistry, aerosols are airborne particles smaller than 50 microns 
whereas splatter is used to denote particles larger than 50 microns. Since they are small enough, aerosol particles stay in air for longer duration, can penetrate lungs and are greatest threats in dentistry. On the other hand, splatter particles cannot remain in air for a long duration. (7) A number of procedures in dentistry are responsible for producing aerosols and splatter including ultrasonic or sonic scaler for oral prophylaxis, air-water syringes used ubiquitously during multiple procedures, high speed rotary handpieces, implant handpieces and air- polishing systems. A very highrisk profession combined with an airborne disease with no vaccine or treatment, where in majority of the patients maybe asymptomatic or carriers; makes protection of the dental personnel, the patients themselves and prevention of contamination and spread a considerably challenging task.

\section{Modes of Transmission}

According to the most recent guidelines published by CDC, the spread of Covid -19 occurs mainly due to close personal contact primary via respiratory droplets when they land on the mouth, eyes or nose of nearby individuals and through direct contact of infected surfaces. The CDC is uncertain about spread of infection solely via aerosols or droplet nuclei and reasserts that airborne transmission over long distances is unlikely. However, dentistry is unique in this regard as rotary instruments create splatter containing water droplets with debris and microorganisms. This splatter contains aerosols that usually settles on the nearby surfaces or the dental provider and acts a mode of transmission. Since elective dental procedures can now be performed again, infection control guidelines are modified to keeping in mind that unrecognized asymptomatic and mildly symptomatic patients are responsible for transmission of disease.(8)

Apart from standard precautions, additional transmission-based precautions are recommended by $\mathrm{CDC}$ for A) contact precautions, (Fig.1), B) droplet precautions (Fig. 2) and 3) airborne precautions (Fig 3). These precautions include placement of patients in single patient cubicles. OSHA advices specific engineering designs before elective procedures can be scheduled. Also, care should be taken to not transport patients from different rooms and entire procedure needs to be completed in a single room for the same patient. Autoclavable or disposable equipment and personal protective equipment should be used all patients. Rooms and all exposed surfaces should be adequately cleaned and disinfected between patients. Hand hygiene forms an important aspect to prevent all three types of transmission.

\section{Patient and Dental Personnel Protection}

As we progress from emergency dental care to more elective dental treatment, preventing the spread of infection and protection of all the personnel involved is imperative. Center for disease control and the American dental association have recently come out with guidelines to successfully resume practice.

1) Before the patient appointment: Communication and careful planning is the key to a successful appointment. Patients should be advised to maintain social distancing and to visit the dental office alone and just 10 minutes before the appointment in order to reduce crowding or to wait in parking lots. (9). The temperature of the patient can also be checked before any procedures. Tele dentistry can be utilized to screen patients before their scheduled appointments to rule out symptoms like fever, shortness of breath, cough or overseas travel and close association with a Covid positive family member.

2) At the dental appointment visit: Standard precautions assume that every patient is potentially infectious whether proven or otherwise. As the mode of transmission is airborne and droplet spread, the PPE and engineering requirements have been altered. Operatories should be isolated with barriers if they have multiple chairs in an open bay. CDC recommends full length gowns, gloves, N95 respirators and face shields during aerosol producing procedures. (Fig 4). N95 masks should be fit tested to have a tight fit. They prevent exposure to small aerosols and droplets and should be discarded when damaged or soiled. Training needs to be provided to all personnel as regards donning and doffing the PPE. High velocity evacuation and four handed dentistry is mandatory when using aerosol producing equipment. All staff should wear masks, gloves, goggles and face shields if coming within six feet of patient. Ideally all PPE should be discarded for every patient or when it is visibly soiled. Laundry service needs to be provided at the office if scrubs are worn. (8) 3) Post dental appointment: All visible surfaces like computer screen, keyboards, tubing, light switches, counter tops etc. should be covered with disposable plastics and discarded after each patient appointment. Dirty surfaces should be cleaned with soap-water, before disinfection with approved disinfectants that meet EPAs criteria against SARS-COV2. The personnel responsible for this should follow proper hand hygiene and be required to use the entire PPE.

It is important for every dental office or dental care setting test the policy changes before hand and be comfortable with its implementation before scheduling patients. Also, additional time should be scheduled per and in between procedures for proper disinfection measures.

\section{Economic Implications}

The profession of dentistry involves the working of the dentist in close association to an individual's oral cavity. The dental procedures involved tend to generate aerosols (a mixture of water that constitute patient's saliva or blood) owing to the use of an air-rotor or highspeed handpiece (from a dental instrument like high speed hand piece). Studies have reported the spread of the novel coronavirus via air droplets and these aerosols could be implicated in the spread of several diseases including the covid-19 virus(10). Studies have suggested that dentists are at the highest risk at contracting the virus due to cross infection from the patient $(10,11)$. Hence, several health regulatory bodies around the world have advised dental health professionals against performing regular elective dental treatment procedures such as orthodontic activation procedures, extractions, dental restorations, aesthetic procedures(11).

The registered dentists were informed to provide only emergency dental treatment in an attempt to limit the exposure of the dentist to the covid-19 virus. Although, this is a very commendable move, it has serious implications on the financial aspect. Since several dental practitioners and dental schools, globally, have closed their clinics during this period, and it has resulted in heavy financial loses. In fact, studies have reported that dentist are expecting a $70 \%$ financial loss this year. Moreover, in order to prevent the transmission of the disease from the patient to the dentist, there arises a need for the use of additional personal protective equipment (PPE) and restructuring of clinical spaces in certain cases (12). The cost of the PPE has been currently increased owing to the increasing demand and low availability, thus increasing monetary losses that cannot be compensated by the patient's treatment fees. Overall costs can be reduced by the use of regular PPE for the healthy patient and additional PPE that is not restricted to N95 masks, face shields for a recently exposed patient or a patient from a high-risk zone. However, since the risk of contracting the virus from asymptomatic carriers also high, that makes it imperative to use additional PPE while treating every patient. Furthermore, the use of HEPA filters have currently been recommended and the high price makes purchase difficult. 
In order to address these issues and concerns, the governments of several high-income countries have extended their financial support to dental practices including the US, Canadian, UK and Irish government who are willing to reimburse dentists due to the losses from the COVID19 outbreak. On the other hand, no measures to address these concerns have been proposed from the low-income and middle-income countries. It is highly recommended that governing regulatory bodies and authorities support these dental practices which are on the verge of closure due to incurred financial losses.

During this pandemic, medical healthcare workers have been on the frontline towards fighting off this crisis, and with the current lack of medical doctors, dentists have been called upon to assume the duties of the medical professionals $(13,14)$. Hence, it is imperative for the government to ensure that the needs of the dentists are being met and addressed and provisions are being made as well as offered to them in order to save the profession. The dentists should evaluate overhead costs and make informed decisions. They should also understand that full recovery post reopening the practices would take up to 18 months to establish $70-80 \%$ of the income prior to the pandemic. They should also demonstrate empathy towards the coworkers and staff and decide against laying off any staff member. The dentists should also bear in mind the fact that most patients may not be able to afford the entire treatment costs and could work by offering discounts, work on payment installments or propose coinsurance plans.

\section{Pshycological Implications}

The repercussions of the covid-19 pandemic, that has affected millions of people globally, owing to the isolation and quarantine as well as reduced mortality has resulted in considerable psychological stress and fear. With the prolonged incubation period of the covid-19 currently at 14 days, it is remotely impossible to determine the time period as well as the individual's exposure to the virus. Moreover, the lack of a current treatment plan, medication or vaccine further elevates people's fears and anxiety of contracting the virus(15).

The most affected population is the healthcare workers who are constantly busy with treating the patients. Due to the close proximity and constant interaction which increases the already existing tremendous psychological toll. Since, studies that reported the spread of the virus via the droplets, this increases the likelihood of dentists and dental healthcare workers of getting infected and further spreading the virus(16). Dental professionals and auxiliary are primarily at risk of contracting the virus during an outbreak this the COVID-19 due to the aerosols and droplets associated with the dental treatment procedures. These aerosols consist of fine particles which could harbor the virus and contain it for up to three hours. This creates fear amongst the dental healthcare professionals and invokes skepticism in them with regard to rendering dental treatment to the general population $(17,18)$. These fears have been amplified by the news of the death of the seven dental professionals and a senior dental nurse in Italy and the UK respectively from COVID-19.

With the lockdown in place, even patients requiring dental treatment have been skeptical about acquiring dental treatment due to the risk of transmission from the healthcare worker to the patient. Studies have reported about the sufferings of the patients requiring urgent and emergency dental treatment due to the non-availability of the dentist(19). Current job losses and financial crunches also makes it difficult for patients to seek dental treatment in such situations. Moreover, the majority of the dentists are afraid of providing treatment to any patient reporting suspicious symptoms. Owing to the rapid progression of the disease across several countries in a very short span of time, it is justifiable on the part of the dentists to decline dental treatment to the population. Furthermore, dentists are fearful of spreading the disease from their dental practice to their family members, since the virus can stay active on various surfaces for a few hours to a few days combined with the lengthened incubation period much before symptoms can develop. The healthcare workers are also afraid of being quarantined as well the thought of watching their family suffer due to possible infection from the virus(12). Even, the financial burden on the healthcare and cost incurred during treatment induces a lot of stress in one's mind since, most facilities are sponsored by the government or state. Hence, it is currently advisable to defer all elective treatment and provide only emergency dental services. The dentists and patients can also seek help from consulting psychologists or psychiatrists in order to overcome anxiety during this crisis(20).

\section{Ethical Implications}

Although the dental regulatory bodies had temporarily instructed registered dental practioners to suspend elective dental care and render only emergency services, which is against the ADA code of dentists to "have the benefit of the patient as their primary goal.," it is necessary to understand that this is being done in interests of the general population in order to protect them from the COVID-19, which is in accordance with the principles of Nonmaleficence ("do no harm"), Beneficence ("do good"), and Justice ("fairness")(21). These measures help to limit the spread of the aerosol particles in the dental office that is generated by high-speed handpieces and ultrasonic scaling units. The PPE should be also conserved and used for patients with urgent and emergency needs(22). By cutting corners in the use of PPE, it violates the principle of non-maleficence (do no harm) as it puts the patient and health professional at risk. If the dentist has exhausted his supply of PPE, he has the right to not render services and in these cases, it is not appropriate to send patients of record to the local emergency department, public health clinic, or dental school for treatment, as these settings may be overburdened already with direct disease response. However, it may be the duty of the dentist in such situations to refer the patient to another fellow dentist(23). Some dentists have been continuing their practice in order to prevent economic losses and retain employees; however, they must realize that they may be putting the health of the employees at risk. Overall, we need to demonstrate empathy towards our fellow dentists and community and consider that there is currently a financial strain on everyone in the practice. However, when money drives the decision process, ethics often will be compromised and during this challenging time, we need to balance the interests of patients, office staff members, and the entire community(23).

\section{Conclusion}

After studying what the studies have reported, it is imperative to understand that the dental professionals should not be placed at unnecessarily high risk than would be morally acceptable and that practice post the Covid pandemic will definitely be different than before(24). It should also be established that since dentists may not have access to proper PPE such as gowns, gloves, FFP3 masks and eye protection due to the of lack of availability, they may be at risk of cross infection from asymptomatic covid-19 carriers or not be able to practice at all. Hence dentists can request for the testing of suspicious patients as well as choose to temporarily defer treatment to high risk patients. The dentists should also realize that rebuilding the practice may take time and that they should be patient during the process. They can calculate the losses during the period, draft a plan for the overhead expenses, seek out loans from the government in order to overcome financial drawbacks. They should seek 
psychological help if they find it difficult to cope with the anxiety during the process and use this crisis as an opportunity to reinvent the way they have been working and dealing with their practice.
Figures Are Source: CDC (Centers For Disease Control and Prevention)

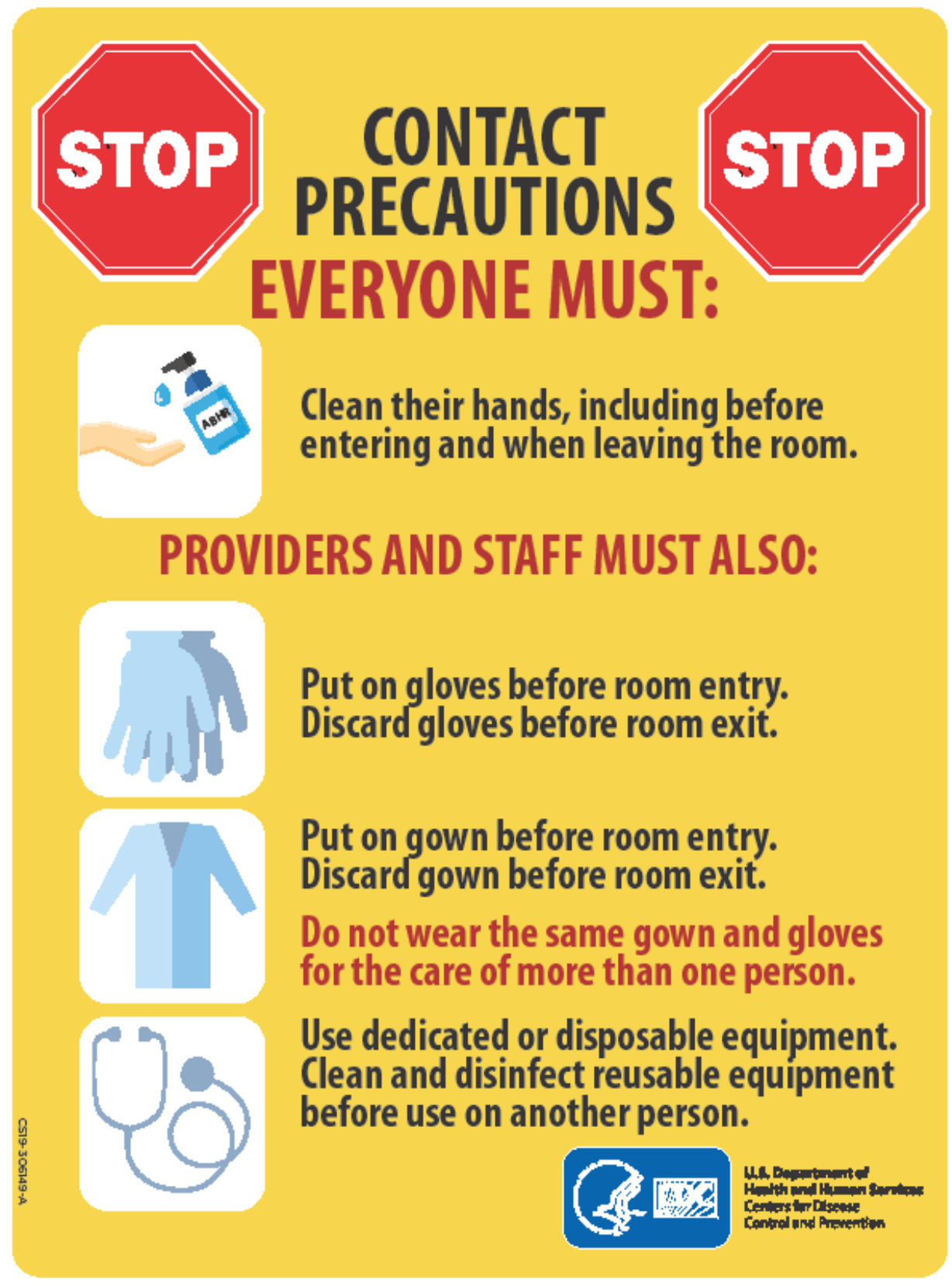




\section{COVID-19 Personal Protective Equipment (PPE) for Healthcare Personnel}

\section{Preferred PPE - Use $N 95$ or Higher Respirator}

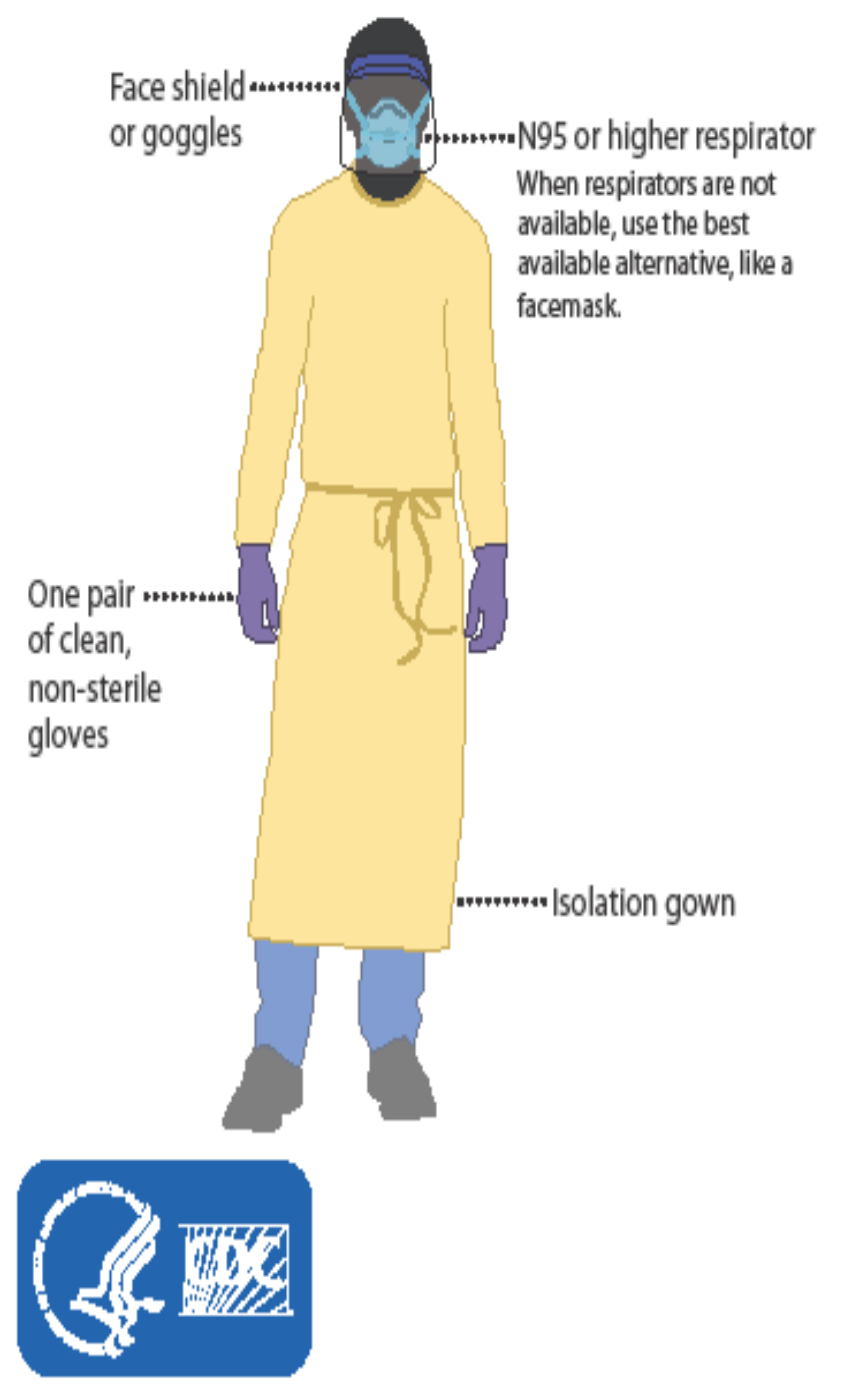

\section{Acceptable Alternative PPE - Use Facemask}

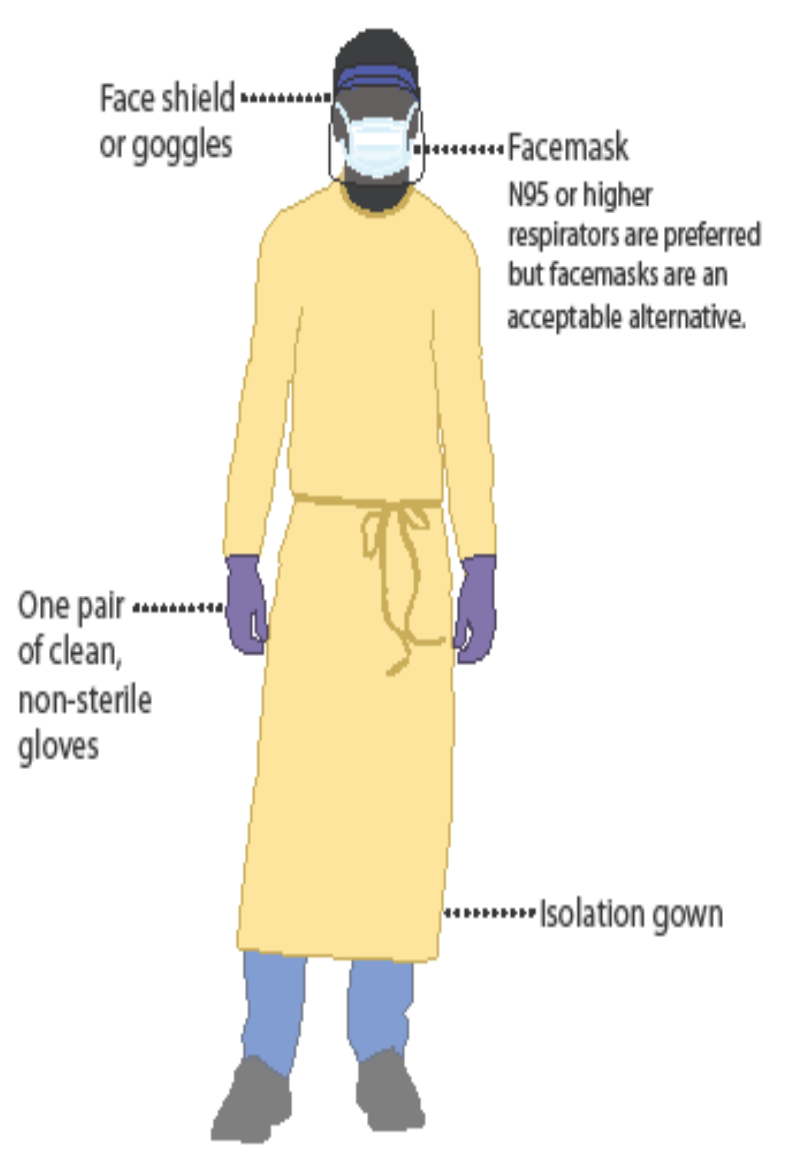




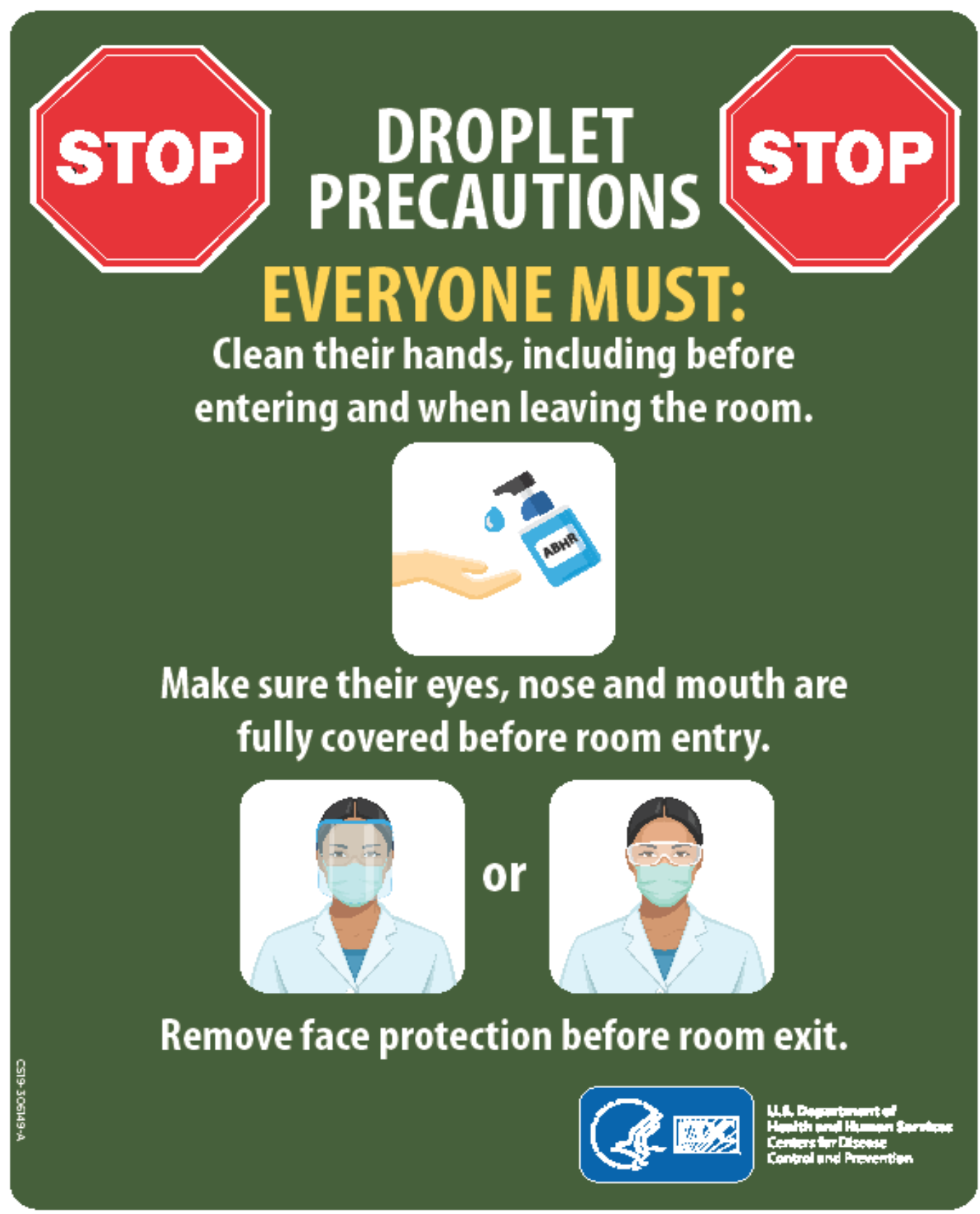

Figure 3: CDC list of airborne precaution 


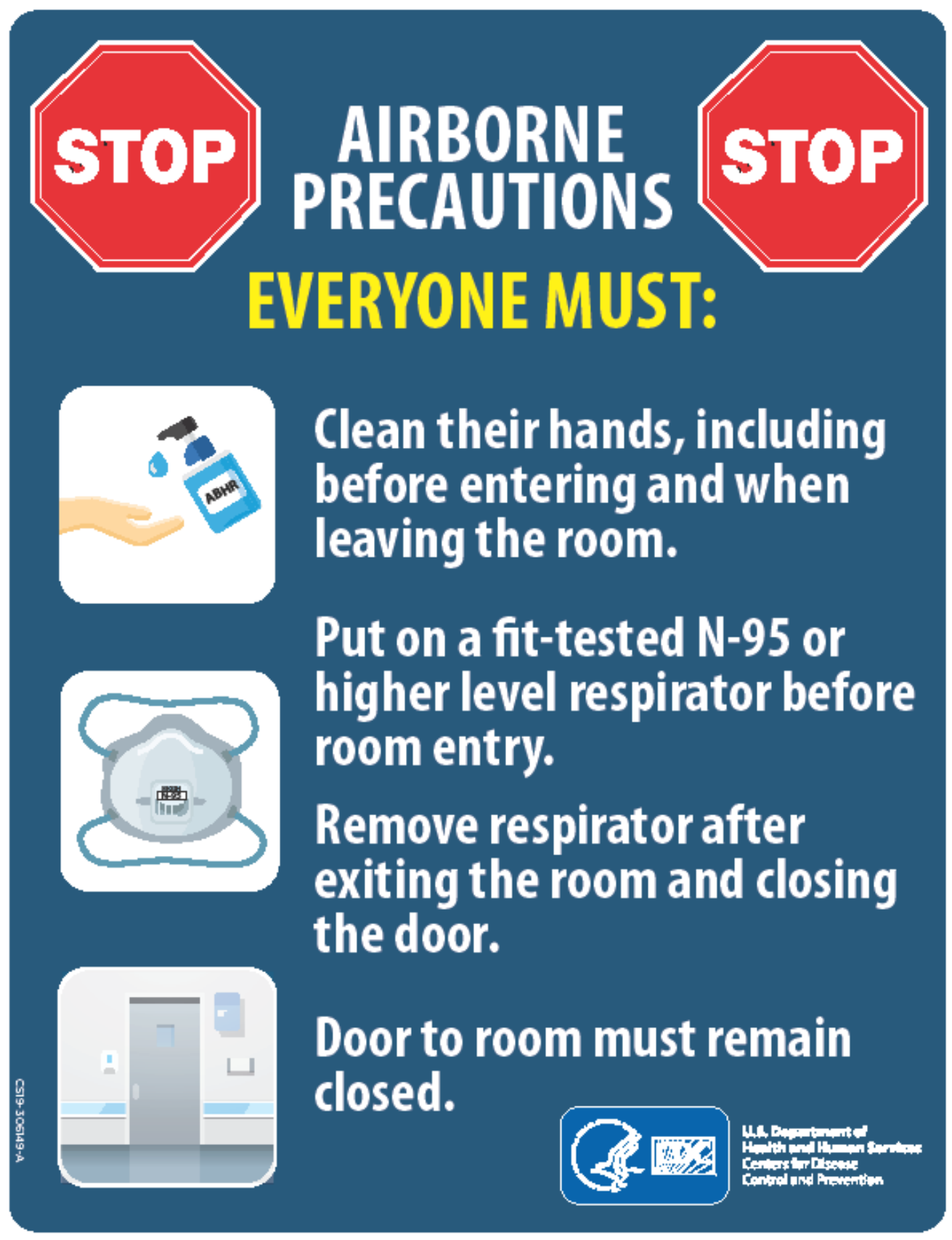

Figure 4: CDC Covid-19 PPE illustration

Disclaimer: Use of the material, including any links to the materials on the CDC, does not imply endorsement by CDC

\section{References}

1. Xie M, Chen Q. Insight into 2019 novel coronavirus - An updated interim review and lessons from SARS-CoV and MERS-CoV. International Journal of Infectious Diseases. 2020;94:119-24.

2. Zhu N, Zhang D, Wang W, Li X, Yang B, Song J, et al. A Novel Coronavirus from Patients with Pneumonia in China, 2019. New England Journal of Medicine. 2020;382(8):727-33.

3. Chan KW, Wong VT, Tang SCW. COVID-19: An Update on the Epidemiological, Clinical, Preventive and Therapeutic
Evidence and Guidelines of Integrative Chinese-Western Medicine for the Management of 2019 Novel Coronavirus Disease. Am J Chin Med. 2020;48(3):737-62.

4. Whittaker A, Anson M, Harky A. Neurological Manifestations of COVID-19: A review. Acta Neurol Scand. 2020.

5. Rothan HA, Byrareddy SN. The epidemiology and pathogenesis of coronavirus disease (COVID-19) outbreak. J Autoimmun. 2020;109:102433.

6. OSHA. Guidance on Preparing Workplaces for COVID-19. 2020.

7. Micik RE, Miller RL, Mazzarella MA, Ryge G. Studies on dental aerobiology. I. Bacterial aerosols generated during dental procedures. J Dent Res. 1969;48(1):49-56. 
8. CDC Coronavirus disease - Interim Infection Prevention and Control Recommendations for Patients with Suspected or Confirmed Coronavirus Disease 2019 (COVID-19) in Healthcare Settings. 5-18-2020.

9. Hua CG, Liu ZQ, Wang Q, Yang Z, Xu QH, Zhang J. [Strategy of dental clinics to cope with the epidemic period of infectious diseases based on the experience of corona virus disease outbreak]. Hua xi kou qiang yi xue za zhi = Huaxi kouqiang yixue zazhi $=$ West China journal of stomatology. 2020;38(2):117-21.

10. Baseer MA, Ansari SH, AlShamrani SS, Alakras AR, Mahrous $\mathrm{R}$, Alenazi AM. Awareness of droplet and airborne isolation precautions among dental health professionals during the outbreak of corona virus infection in Riyadh city, Saudi Arabia. Journal of clinical and experimental dentistry. 2016;8(4):e379e87.

11. Baghizadeh Fini M. What dentists need to know about COVID19. Oral oncology. 2020;105:104741.

12. Ather A, Patel B, Ruparel NB, Diogenes A, Hargreaves KM. Coronavirus Disease 19 (COVID-19): Implications for Clinical Dental Care. Journal of endodontics. 2020;46(5):584-95.

13. Li G, Chang B, Li H, Wang R, Li G. The Role of Dental Professionals in Pandemic Events and Disasters Response. Disaster medicine and public health preparedness. 2020:1-13.

14. Meng L, Hua F, Bian Z. Coronavirus Disease 2019 (COVID19): Emerging and Future Challenges for Dental and Oral Medicine. Journal of dental research. 2020;99(5):481-7.

15. Ashok N, Rodrigues JC, Azouni K, Darwish S, Abuderman A, Alkaabba AA, et al. Knowledge and Apprehension of Dental Patients about MERS-A Questionnaire Survey. Journal of clinical and diagnostic research : JCDR. 2016;10(5):ZC58-62.

16. Shacham M, Hamama-Raz Y, Kolerman R, Mijiritsky O, BenEzra M, Mijiritsky E. COVID-19 Factors and Psychological Factors Associated with Elevated Psychological Distress among Dentists and Dental Hygienists in Israel. International journal of environmental research and public health. 2020;17(8).

17. Khader Y, Al Nsour M, Al-Batayneh OB, Saadeh R, Bashier H, Alfaqih M, et al. Dentists' Awareness, Perception, and Attitude Regarding COVID-19 and Infection Control: Cross-Sectional Study Among Jordanian Dentists. JMIR public health and surveillance. 2020;6(2):e18798.

18. Kamate SK, Sharma S, Thakar S, Srivastava D, Sengupta K, Hadi AJ, et al. Assessing Knowledge, Attitudes and Practices of dental practitioners regarding the COVID-19 pandemic: A multinational study. Dental and medical problems. 2020;57(1):11-7.

19. Ahmed MA, Jouhar R, Ahmed N, Adnan S, Aftab M, Zafar MS, et al. Fear and Practice Modifications among Dentists to Combat Novel Coronavirus Disease (COVID-19) Outbreak. International journal of environmental research and public health. 2020;17(8).

20. Qu X, Zhou XD. [Psychological intervention for patients with oral disease during the pandemic period of COVID-19]. Zhonghua kou qiang yi xue za zhi $=$ Zhonghua kouqiang yixue zazhi $=$ Chinese journal of stomatology. 2020;55(4):235-40.

21. Mupparapu M. Editorial: Dental practitioners' role in the assessment and containment of coronavirus disease (COVID19): Evolving recommendations from the Centers for Disease Control. Quintessence international. 2020;51(5):349-50.

22. Coulthard P. Dentistry and coronavirus (COVID-19) - moral decision-making. British dental journal. 2020;228(7):503-5.

23. Ethics Subcommittee of the Council on Ethics B, Judicial A. Ethical practice during the COVID-19 pandemic. Journal of the American Dental Association. 2020;151(5):377-8.

24. Proffitt E. What will be the new normal for the dental industry? British dental journal. 2020;228(9):678-80.
This work is licensed under Creative Commons Attribution 4.0 License

To Submit Your Article Click Here: Submit Article

DOI: $10.31579 / 2690-1919 / 096$

$$
\begin{aligned}
& \text { Ready to submit your research? Choose Auctores and benefit from: } \\
& \text { fast, convenient online submission } \\
& \text { rigorous peer review by experienced research in your field } \\
& \text { rapid publication on acceptance } \\
& \text { authors retain copyrights } \\
& \text { unique DOI for all articles } \\
& \text { immediate, unrestricted online access }
\end{aligned}
$$

At Auctores, research is always in progress.

Learn more www.auctoresonline.org/journals/journal-of-clinicalresearch-and-reports 